\title{
An overview of urethral injury
}

\section{R. Christopher Doiron, MD; Keith F. Rourke, MD, FRCSC}

Division of Urology, University of Alberta, Edmonton, AB, Canada

Cite as: Can Urol Assoc J 2019;13(6Supp14):S61-6. http://dx.doi.org/10.5489/cuaj.5931

\section{Case}

A 37-year old male involved in a high-speed motor vehicle accident is brought to the emergency department for assessment. As the belted passenger of the vehicle, he sustained blunt trauma to the lower abdomen. On initial assessment by the trauma team, the patient is hemodynamically stable but unable to void. A plain-film assessment of the pelvis reveals right-sided pubic rami fractures (Fig. 1) with some associated soft tissue swelling. The trauma team seeks urological assessment.

On physical exam, the patient's bladder is palpable and distended in the midline. There is blood at the urethral meatus; the prostate is impalpable on digital rectal exam, while a "butterfly" hematoma is observed over the scrotum and perineum.

Retrograde urethrogram (RUG) performed at the bedside reveals extravasation of contrast at the level of the bulbomembranous urethra - a complete urethral disruption with no contrast visualized in the bladder (Fig. 2).

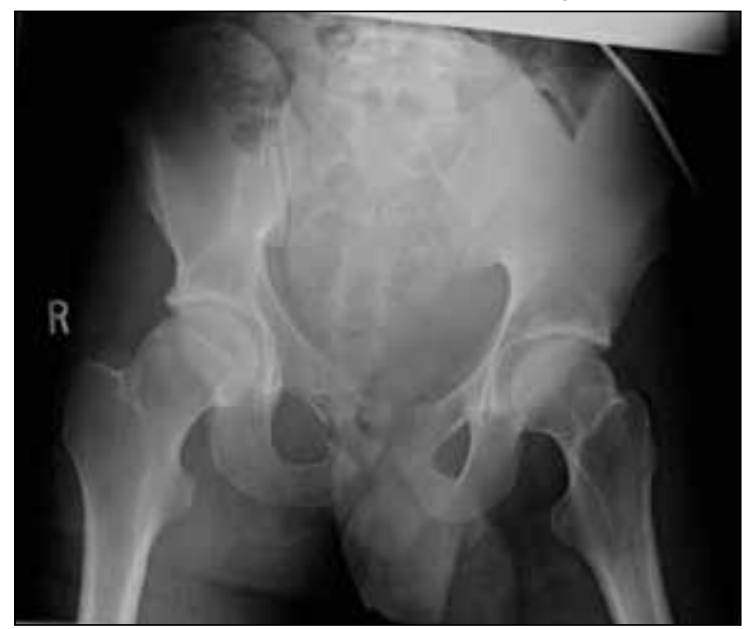

Fig. 1. Pelvic $x$-ray obtained during the initial trauma assessment demonstrating pelvic rami fractures raising the suspicion for a potential pelvic fracture urethral injury (PFUI).

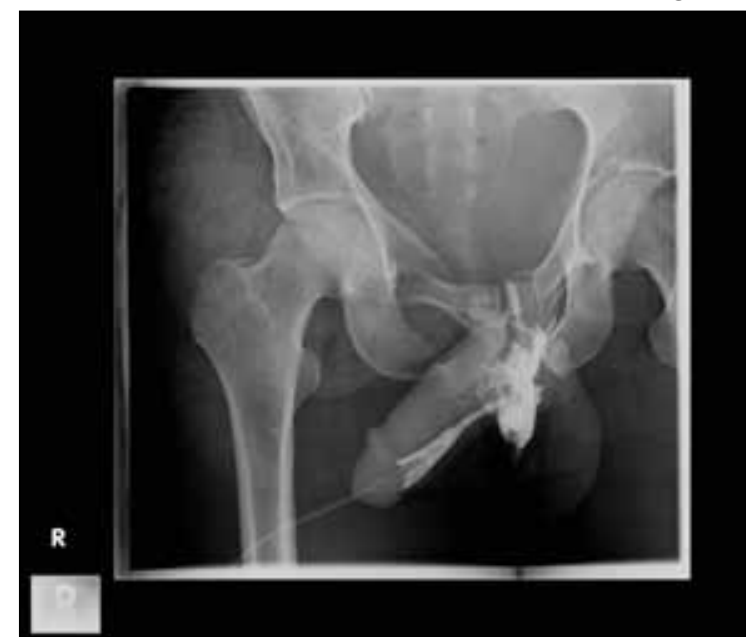

Fig. 2. Results from a retrograde urethrogram performed at initial assessment of the patient in the emergency department. Contrast extravasation can be seen at the level of the bulbomembranous urethra, while no contrast is seen beyond the site of injury, suggesting complete urethral disruption. 


\section{Introduction}

Urethral injuries can first be classified based on location as either anterior or posterior. Anterior urethral injuries are often the result of blunt or penetrating trauma ${ }^{1}$ with the bulbar urethra the most common location affected. ${ }^{2}$ The mechanisms of injury ranges from gunshot wounds to self-inflicted sexual misadventures. In contrast, posterior urethral injuries are most commonly the result of pelvic fracture or iatrogenic trauma during pelvic surgeries. Pelvic-fracture associated urethral injuries (PFUI) are present in $1.5 \%-10 \%{ }^{3,4}$ of injuries resulting in fracture of the pelvis. High-speed motor vehicle accidents are the most common mechanism of injury here, ${ }^{4-6}$ though fall from height is another common mechanism resulting in pelvic fracture and PFUI. Given the relative complexity of PFUI and fact that it's three times more common in the setting of trauma than anterior urethral injury, ${ }^{1}$ PFUI will be the focus of the current review.

\section{Diagnosis of a suspected urethral injury}

\section{Clinical signs/symptoms}

Assessment of a patient suspected of urethral trauma should follow a standard approach to any trauma patient. Given that patients suspected of PFUI are often complex in presentation with multiple associated injuries, additional referring services are often involved in care. The most responsible team at time of initial assessment is often the trauma service, therefore, thorough communication and collaboration is of utmost importance in providing the best urological care.

After hemodynamic stability is confirmed, a thorough genitourinary $(\mathrm{GU})$ exam is required. Blood at the urethral meatus is a common finding in the presence of a urethral injury and PFUI, although its absence does not rule one out. Other findings on inspection may include ecchymosis of the scrotum and/or perineum, while in women, urethral injury should be suspected in the presence of labial edema or blood at the introitus. Given that urinary retention is another common presenting symptom of PFUI, ${ }^{7}$ the bladder may be distended and palpable on abdominal exam. Digital rectal exam (DRE) findings in the setting of urethral trauma may vary from impalpable, particularly in the acute phase of $\mathrm{PFUI}^{7,8}$ secondary to presence of a pelvic hematoma obscuring the prostate to palpation, ${ }^{9}$ or "high-riding" in the case of a partial or complete posterior urethral disruption. Furthermore, DRE should be performed to rule out a rectal injury. ${ }^{8}$

\section{Imaging and flexible cystoscopy}

Plain-film or scout fluoroscopy imaging of the pelvis can identify pelvic fracture or presence of foreign bodies in the $\mathrm{GU}$ tract $\mathrm{t}^{10}$ but has no role in diagnosing urethral injury directly. Furthermore, although potentially useful in the acute trauma setting for ruling out concomitant injuries or in the scenario where a suprapubic catheter (SPC) is to be placed, ${ }^{1}$ there is no role for use of ultrasound, computed tomography $(\mathrm{CT})$, or magnetic resonance imaging (MRI) in the diagnosis of PFUI in the acute setting.

Retrograde urethrogram (RUG) is the diagnostic imaging study of choice in the setting of suspected urethral injury. Partial disruption of the urethra is suggested with active extravasation of contrast with simultaneous bladder filling, while a complete disruption is suggested in the setting of contrast extravasation without visualization of contrast in the bladder. ${ }^{7}$ While the American Association for the Surgery of Trauma (AAST) staging of urethral injury ${ }^{11}$ remains the gold standard staging system, Chapple et $\mathrm{al}^{1}$ suggested a simpler, practical classification system based on RUG findings in their 2004 consensus statement on urethral injury. A RUG will help identify the location and extent of urethral injury and can be helpful in guiding subsequent management decisions.

Bedside flexible cystoscopy may be performed in the acute setting of suspected urethral injury as a diagnostic adjunct with potential for intervention; it can help identify a partial vs. complete urethral injury while primary realignment (PR) with a urethral catheter may be performed with placement of a wire across the injured area. ${ }^{12}$ Bladder drainage is paramount in the acute management of PFUI and PR has been associated with improved outcomes compared with SPC drainage only in terms of eventual stricture severity. ${ }^{13,14}$ Thus, an attempt at PR via bedside flexible cystoscopy is a reasonable and commonly used manoeuvre, recognizing that in the setting of an unstable patient, bladder drainage with SPC placement may be more appropriate (see section on "Immediate primary realignment vs. SPC placement" below).

\section{Guideline review}

In the described case, a complete PFUI is confirmed with RUG following an assessment with clinical signs and symptoms consistent with a urethral injury. The American Urological Association (AUA) urotrauma guideline ${ }^{15}$ is clear on their statement suggesting assessment with RUG when there is blood at the urethral meatus in the setting of pelvic trauma.

The European Association of Urology (EAU) urological trauma guideline similarly recommends evaluation of suspected urethral injury with RUG as the gold standard. ${ }^{16}$

From a Canadian perspective, the authors suggest evaluation of suspected urethral injury with RUG in the acute setting is appropriate; alternatively, the use of flexible cystoscopy is acceptable in appropriately experienced hands. These findings help guide subsequent management decisions. 


\section{Management of PFUI}

When treating urethral injury, timing of the various interventions is often described as immediate: $<48$ hours; delayed: 2-14 days; deferred: $>3$ months. ${ }^{1,9}$ In the immediate setting, when treating a suspected urethral injury, there is no evidence to suggest that a partial urethral injury may be converted to complete disruption. Furthermore, no evidence exists to suggest that attempts at catheterization increase subsequent risk of infection or stricture. ${ }^{7,9}$ In practice, urethral catheterization has often been attempted by the initial assessment team. An attempt at passage of a urethral catheter by an experienced practitioner in the setting of suspected urethral injury is a reasonable first step.

\section{Partial posterior urethral injury}

Placement of a urethral catheter in the setting of a partial urethral injury may result in complete healing without need for further intervention. The injury should be evaluated with urethrography at two-week intervals until healing has occurred. ${ }^{17,18}$

\section{Complete posterior urethral injury}

\section{Case cont'd: Acute treatment (complete posterior urethral injury)}

Bedside cystoscopy is unsuccessful at placing an aligning catheter and the patient is brought to the operating room, where an open cystotomy is performed with combined retrograde and antegrade endoscopic placement of an aligning urethral catheter. Postoperatively, a SPC is left in place in addition to an aligning catheter.

\section{Immediate urethroplasty}

Immediate urethroplasty in the setting of PFUI results in an unacceptably high rate of stricture, erectile dysfunction (ED), and incontinence ${ }^{18}$ and should not be attempted. Furthermore, exploring PFUI in the acute setting risks disrupting a stable pelvic hematoma and has the potential to cause significant bleeding. ${ }^{9}$

\section{Immediate primary realignment vs. suprapubic catheter placement}

There is controversy among urologists involved in managing GU trauma with regard to the optimal acute management of
PFUI. Immediate PR via an endoscopic approach by placing a wire into the bladder and Foley catheter placement over the wire establishes continuity of the lower urinary tract. This can be achieved using flexible and/or rigid cystoscopy, using retrograde or combined retrograde and antegrade cystoscopic approaches. ${ }^{19}$

Evidence guiding practice in this domain is largely from small case series and retrospective studies. Literature supporting PR suggests that achieving realignment in the immediate setting lowers the degree and severity of stricture formation, minimizes fibrosis and scarring at the distraction site, improves the success and ease of future urethroplasty efforts and, in some cases, may negate the need for urethroplasty altogether. ${ }^{19-25}$ Those critical of this approach, however, have pointed out that a selection bias may be introduced into these studies, as those in whom immediate PR is successful may represent a population of PFUI patients with less severe injuries, who may have experienced improved outcomes either way. ${ }^{26}$

On the contrary, proponents of SPC placement alone suggest this technique minimizes prolonged SPC drainage and minimizes length of time to definitive urethroplasty. It has also been shown to be associated with less ED and urinary incontinence. ${ }^{19,27}$ We await the results of a prospective, randomized cohort study designed to help answer this challenging clinical question. ${ }^{26}$

\section{Delayed primary urethroplasty}

Although there is minimal evidence in this space, some small, retrospective case series have shown reasonable results in terms of stricture recurrence, $\mathrm{ED}$, and continence outcomes. ${ }^{28-31}$ Given the excellent results with a deferred approach, further evidence in larger patients populations, ideally in a prospective manner, would be required before making recommendations on this challenging clinical approach.

\section{Guideline review}

In the scenario described in our case - complete traumatic urethral disruption - the AUA guideline states that urinary drainage should be achieved promptly in patients with PFUI, and that an attempt at PR may be performed in hemodynamically stable patients. They warn, however, that prolonged attempts at PR should be avoided and that the primary goal should remain prompt drainage, if not by PR then by SPC..$^{15}$

The EAU guideline has a more thorough discussion of treatment options in the setting of PFUI with complete disruption, as in the case presented. They do not, however, commit to recommending one approach over the other, and discuss either PR or SPC with deferred definitive treatment as acceptable options. They state that immediate urethro- 


\section{Case followup}

The patient is discharged from the hospital and brought to the office for urological evaluation six weeks following his injury. His urethral catheter is removed, his SPC is plugged, and the patient undergoes an attempted trial of void. The patient is unable to void and subsequently the SPC is left in situ for drainage.

At 12 weeks post-injury, a RUG is performed. RUG combined with an attempted voiding cysto-urethrogram reveals complete urethral obliteration at the bulbomembranous junction with suggestion of a long urethral defect (Fig. 3). Subsequent combined RUG and antegrade cystoscopy through the suprapubic tract termed an "up-and-downogram" - delineates a $2 \mathrm{~cm}$ stenosis at the bulbomembranous junction (Fig. 4). With the stricture length and location confirmed, the patient is booked for a posterior urethroplasty via a perineal approach, which he undergoes uneventfully at five months post-injury.

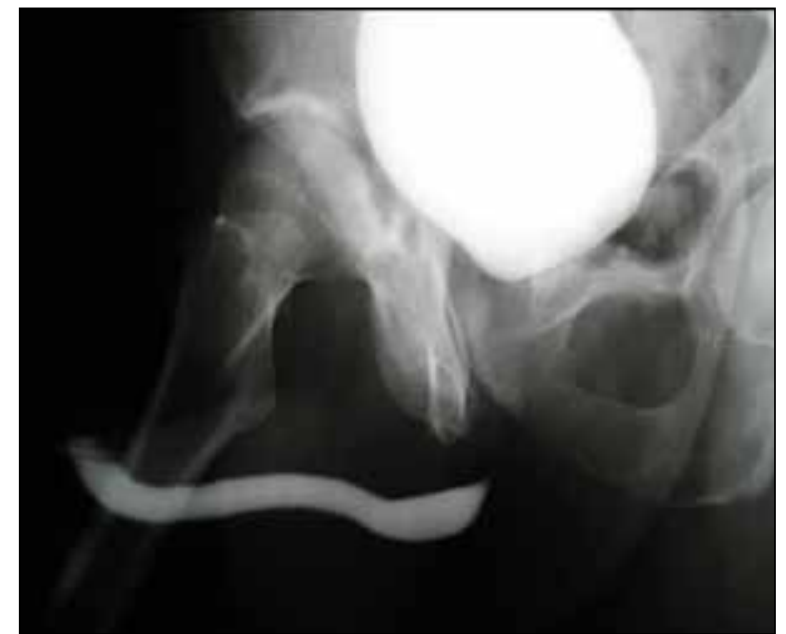

Fig. 3. Results of a combined retrograde urethrogram and attempted voiding cystourethrogram 12 weeks following pelvic fracture urethral injury and six weeks following removal of aligning urethral catheter. There is complete bulbomembranous urethral obliteration with the suggestion of a lengthy but poorly delineated urethral defect due to closure of the bladder neck.
There are no specific statements or recommendations from either the AUA or EAU guideline regarding length of catheterization following PR. The EAU guideline, however, does note that in most reported series of PR, catheterization lasted from 4-8 weeks prior to an observed trial of void. The authors would agree that a period of catheterization of at least four weeks following PR is warranted.

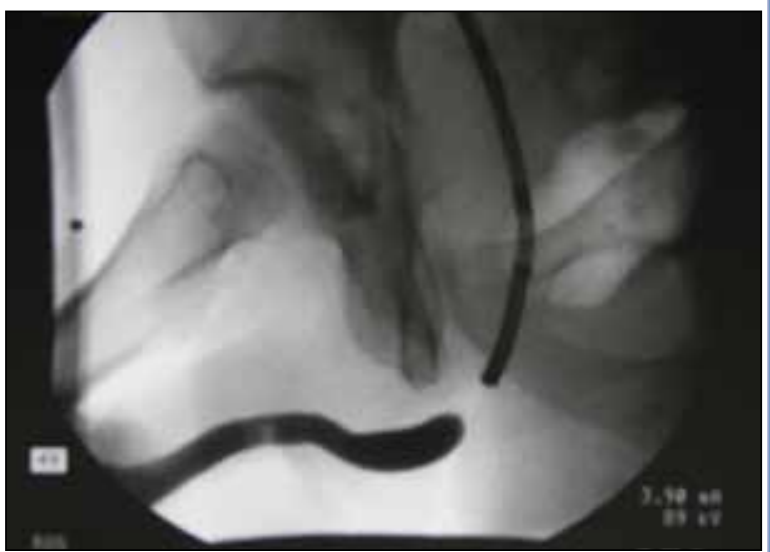

Fig. 4. Results of combined antegrade cystoscopy (via the suprapubic tract) with simultaneous retrograde urethrogram, known as an "up-and-downogram." This confirms complete bulbomembranous urethral obliteration with a $2 \mathrm{~cm}$ posterior urethral defect. plasty cannot be recommended given the current state of the evidence and potential risk of suboptimal outcomes and complications. ${ }^{16}$

The authors acknowledge the ongoing debate regarding PR vs. SPC drainage alone and agree that one cannot be considered superior over the other at this point. From a Canadian perspective, in a resource-limited operative setting, the authors recognize that there may be barriers to PR should it require an operative setting, and support either strategy as an acceptable approach as we await results from a prospective tria ${ }^{29}$ looking to provide further guidance in this clinical scenario.

\section{Deferred urethroplasty}

An approach of deferred urethroplasty - considered as primary urethroplasty $>3$ months following initial PFUI would be considered the favoured approach to complete urethral disruption and obliteration secondary to PFUI by most, ${ }^{32}$ with success rates reported as high as $85-97 \%{ }^{33,34} \mathrm{~A}$ well-established perineal approach to posterior urethroplasty for PFUI ${ }^{35}$ describes four manoeuvres in order to bridge the distraction defect: extensive bulbar urethral mobilization, splitting of the corporal bodies, inferior pubectomy, and corporal rerouting, performed in a stepwise approach as necessary to achieve a tension-free anastomosis. 


\section{Guideline review}

The AUA guidelines do not specifically make a statement regarding treatment for stricture following PR. However, they do make a vague suggestion that either urethroplasty or direct visual internal urethrotomy (DVIU) would be acceptable options. The approach selected would depend on the length, location, and density of the stricture, as well as patient preference. ${ }^{15}$

The EAU guidelines suggest that for those requiring deferred urethroplasty, standard treatment would be a single-stage perineal approach, after waiting for a minimum of three months. They further suggest that short, non-obliterative strictures following PR can be managed endoscopically with DVIU or urethroplasty, and that it should be recognized that repeated attempts at endoscopic management or dilation would be considered palliative and should be avoided when possible. ${ }^{16}$

In the current case, the patient has a completely obliterated urethral stenosis and in this specific instance, endoscopic procedures are very unlikely to offer a durable response. The AUA guideline on urethral stricture ${ }^{36}$ recommends that delayed urethroplasty should be performed instead of endoscopic procedures after urethral obliteration due to PFUI. In the case of complete urethral obliteration after PFUI, "cut to the light" procedures are rarely successful outside of the short-term and have a significant risk of transfusion and rectal injury. Repeated endoscopic maneuvers, including intermittent catheterization, should be avoided because they are not successful in the majority of PFUI, increase patient morbidity, and may delay the time to anastomotic reconstruction.

The authors suggest that treatment of stricture recurrence following PR should be a shared decision with an informed patient, recognizing the risks and benefits of formal urethroplasty vs. endoscopic management vs. prolonged catheterization. From a Canadian perspective, the authors recognize the potentially prolonged catheterization time many patients experience as they await referral to a urologist experienced in performing posterior urethroplasty. This may result in a disproportionate amount of attempts at endoscopic management but is the reality of our resource-limited system. Presuming an informed discussion with the patient and recognition of the palliative nature of repeated endoscopic attempts, this may be an appropriate approach. However, for those in whom formal urethroplasty is a viable option, and should the patient be in agreement, the authors prefer this approach, given the high success rate and definitive nature of the treatment.

\section{Complications of PFUI}

It is of utmost importance that PFUI patients receive adequate followup, as many will develop GU complications as a result of their injury; these complications may include stricture formation, urethrocutaneous fistula, ED, urinary incontinence, and pain. In their guidelines, the AUA states that patients should be surveyed for at least one year using some combination of uroflowmetry, RUG, and/or cystoscopy. The EAU guidelines make no specific reference to followup after PR for PFUI. The authors concur with the $A \cup A$ recommendation that patients should receive close urological followup for at least one year following PFUI.

The debate regarding potential complications of PFUI is perhaps most present in the setting of the discussion around immediate SPC placement vs. primary realignment for treatment of PFUI with complete posterior urethral disruption (see section on "Immediate primary realignment vs. suprapubic catheter placement" for discussion and review of evidence).

\section{Anterior urethral injury}

\section{Blunt injuries of the anterior urethra}

Blunt injuries to the anterior urethra, often the result of a "straddle injury" to the bulbar urethra, result in significant contusion to the spongiosus with possible significant hematoma of the perineum. For these reasons, immediate repair is contraindicated. ${ }^{1}$ The AUA and EAU trauma guidelines ${ }^{15,16}$ are in agreement that SPC drainage or PR with urethral catheter are both options in the acute setting. Depending on the degree of injury, patients may re-canalize with PR alone, however, they should be followed closely given the risk of anterior urethral stricture formation.

\section{Penetrating anterior urethral injury}

Penetrating injuries of the anterior urethra, in the absence of other complicating factors, should be explored immediately with attempted primary repair. Injured tissue should be debrided and urethral ends spatulated with primary reanastomosis. ${ }^{15,16}$ Some have suggested the defects of $2-3 \mathrm{~cm}$ of the bulbar urethra and up to $1.5 \mathrm{~cm}$ of the penile urethra are amenable to spatulation and primary anastomosis. ${ }^{9}$

\section{Summary}

Posterior urethral injuries in the setting of pelvic fracture can be challenging cases to manage in the acute setting, with challenging clinical decision-making in potentially unstable patients with significant comorbid injuries. These patients' subsequent risk of complications, regardless of immediate treatment decisions, can be devastating and they require close attention and followup. Given that long-term outcomes with respect to urethral patency remain acceptable in the hands of those experienced in managing posterior urethral injury, these 
Doiron et al

practitioners should be sought out for patient care assistance when they are not available in the acute setting.

Competing interests: Dr. Rourke has participated in advisory board meetings for and is a shareholder of Boston Scientific; and has participated in clinical trials supported by Red Leaf Medical. Dr. Doiron reports no competing personal or financial conflicts.

This paper has been peer reviewed.

\section{References}

1. Chapple C, Barbagli G, Jordan G, et al. Consensus statement on urethral trauma. BJU Int 2004;93:11951202. hrtps://doi.org/10.1111/i.1464-410x.2004.04805.x

2. Park S, McAninch JW. Straddle injuries to the bulbar urethra: Management and outcomes in 78 patients. J Urol 2004;171:722-5. https://doi.org/10.1097/01.ju.0000108894.09050.c0

3. Brandes S, Borrelli J Jr. Pelvic fracture and associated urologic injuries. World J Surg 2001;25:1578-87. https://doi.org/10.1007/s00268-001-0153-x

4. Biurlin MA, Fantus RJ, Mellett MM, et al. Genitourinary injuries in pelvic fracture morbidity and mortality using the National Trauma Data Bank. J Trauma 2009;67:1033-9. https://doi.org/10.1097/ TA.0b013e3181bb8d6c

5. Palminteri E, Berdondini E, Verze $P$, et al. Contemporary urethral stricture characteristics in the developed world. Urology 2013;81:191-6. https://doi.org/10.1016/i.urology.2012.08.062

6. Basta AM, Blackmore CC, Wessells H. Predicting urethral injury from pelvic fracture patterns in male patients with blunt trauma. J Urol 2007;177:571-5. https://doi.org/10.1016/i.juro.2006.09.040

7. Mundy A, Andrich D. Urethral trauma. Part I: Introduction, history, anatomy, pathology, assessment, and emergency management. BJU Int 2011;108:310-27. https://doi.org/10.1111/i.1464410X.2011.10339.x

8. Figler $B$, Hoffler $C E$, Reisman $W$, et al. Multidisciplinary update on pelvic fracture associated bladder and urethral injuries. Injury 2012;43:1242-9. https://doi.org/10.1016/i.injury.2012.03.031

9. Brandes S. Initial management of anterior and posterior urethral injuries. Urol Clin North Am 2006;33:8795. htrps://doi.org/10.1016/j.ucl.2005.10.001

10. Kommu SS, Illahi I, Mumtaz F. Patterns of urethral injury and immediate management. Curr Opin Urol 2007;17:383-9. https://doi.org/10.1097/MOU.0b013e3282fod5fd

11. Moore EE, Cogbill TH, Malagoni MA, et al. Organ injury scaling. Surg Clin North Am 1995; 75: 293-303. https://doi.org/10.1016/S0039-6109(16)46589-8

12. Kielb SJ, Voeltz ZL, Wolf JS. Evaluation and management of traumatic posterior urethral dissuption with flexible cystourethroscopy. J Trauma 2001;50:36-40. https://doi.org/10.1097/00005373200101000-00006

13. Koraitim MM. Effect of early realignment on length and delayed repair of post-pelvic fracture urethral injury. Urology 2012;79:912-5. hitps://doi.org/10.1016/j.urology.2011.11.054

14. Balkan $\mathrm{E}$, Kilic N, Dogruyol $\mathrm{H}$. The effectiveness of early primary realignment in children with posterior urethral injury. Int I Urol 2005;12:62-6. https://doi.org/10.1111/i.1442-2042.2004.00978.x

15. Morey AF, Brandes S, Dugi DD 3rd, et al. Urotrauma: AUA guideline. J Urol 2014;192: 327-35. https://doi.org/10.1016/i.juro.2014.05.004

16. Summerton DJ, Djakovic N, Kitrey ND, et al. Guidelines on urological trauma. Available at: hittp://uroweb. org/guideline/urological-trauma.Accessed Feb. 2, 2019

17. Koraitim MM. Pelvic fracture urethral injuries: Evaluation of various methods of management. J Urol 1996;156:1288-91. https://doi.org/10.1016/S0022-5347(01)65571-X
18. Koraitim MM. Pelvic fracture urethral injuries: The unresolved controversy. J Urol 1999;161:1433-41. https://doi.org/10.1016/S0022-5347(05)68918-5

19. Kim FJ, Pompeo A, Sehrt D, et al. Early effectiveness of endoscopic posterior urethra primary alignment. J Trauma Acute Care Surg 2013;75:189-94. https://doi.org/10.1097/TA.0b013e31829bb7c8

20. Patterson DE, Barrett $\mathrm{DM}$, Myers RP, et al. Primary realignment of posterior urethral injuries. J Urol 1983;129:513-6. https://doi.org/10.1016/S0022-5347(17)52209-0

21. Mouraviev VB, Coburn M, Santucci RA. The treatment of posterior urethral disruption associated with pelvic fractures: Comparative experience of early realignment vs. delayed urethroplasty. I Urol 2005; 173:873-6. https://doi.org/10.1097/01.ju.0000152145.33215.36

22. Leddy LS, Vanni AJ, Wessells $\mathrm{H}$, et al. Outcomes of endoscopic realignment of pelvic fracture associated urethral injuries at a level 1 trauma centre. J Urol 2012;188:174-8. https://doi.org/10.1016/i. juro.2012.02.2567

23. Moudouni SM, Patard JJ, Manunta A, et al. Early endoscopic realignment of post-traumatic posterior urethral dissuption. Urology 2001;57:628-32. https://doi.org/10.1016/S0090-4295(00)01068-2

24. Kulkarni SB, Barbagli G, Kulkani JS, et al. Posterior urethral stricture after pelvic fracture urethral distraction defects in developing and developed countries, and choice of surgical technique. J Urol 2010;183:104954. https://doi.org/10.1016/i.juro.2009.11.045

25. Barrett K, Braga LH, Farrokhyar F, et al. Primary realignment vs. suprapubic cystostomy for the management of pelvic fracture-associated urethral injuries: A systematic review and meta-analysis. Urology 2014:83:924-9. https://doi.org/10.1016/i.urology.2013.12.031

26. Moses RA, Selph JP, Voelzke BB, et al. An American Association for the Surgery of Trauma (AAST) prospective multicentre research protocol: outcomes of urethral realignment vs. suprapubic cystostomy after pelvic fracture urethral injury. Trans/ Androl Urol 2018;7:512-20. hitps://doi.org/10.21037/tau.2017.11.07

27. Tausch TJ, Morey AF, Scott JF, et al. Unintended negative consequences of primary endoscopic realignment for men with pelvic fracture urethral injuries. J Urol 2014;192:1720-4. https://doi.org/10.1016/j. juro.2014.06.069

28. Lumen $\mathrm{N}$, Hoebeke $\mathrm{P}$, Troyer $\mathrm{BD}$, et al. Perineal anastomotic urethroplasty for posttraumatic urethral stricture with or without previous urethral manipulations: A review of 61 cases with long-term followup. J Urol 2009;181:1196-1200. https://doi.org/10.1016/i.juro.2008.10.170

29. Aboutaieb $R$, Sarf $I$, Dakir $M$, et al. Surgical treatment of traumatic ruptures of the posterior urethra. Prog Urol 2000; 10:58-64.

30. Sfaxi $M$, El Atat $R$, Ben Hassine $L$, et al. Surgical treatment of post-traumatic complete urethral rupture: Deferred urgent urethral suture or delayed repair? Prog Urol 2006;16:464-9.

31. Scarberry K, Bonomo J, Gomez RG. Delayed posterior urethroplasty following pelvic fracture urethral injury: Do we have to wait 3 months? Urology 2018;116:193-7. https://doi.org/10.1016/i.urology.2018.01.018

32. Mundy AR, Andrich DE. Urethral trauma. Part II: Types of injury and their management. BJU Int 2011;108:630-50. https://doi.org/10.1111/i.1464-410X.2011.10340.x

33. Flynn BJ, Delvecchio FC, Webster GD. Perineal repair of pelvic fracture urethral distraction defects: Experience in 120 patients during the last 10 years. J Urol 2003;170:1877-80. https://doi.org/10.1097/01. ju.0000091642.41368.f5

34. Cooperberg MR, McAninch JW, Alsikafi NF, et al. Urethral reconstruction for traumatic posterior urethral disruption: Outcomes of a 25-year experience. J Urol 2007;178:2006-10. https://doi.org/10.1016/i. juro.2007.07.020

35. Webster GD, Ramon J. Repair of pelvic fracture posterior urethral defects using an elaborated perineal approach: Experience with 74 cases. J Urol 1991;145:744-8. https://doi.org/10.1016/S00225347(17)38442-2

36. Wessells $\mathrm{H}$, Angermeier KW, Elliott $\mathrm{S}$, et al. Male urethral stricture: American Urological Association guideline. J Urol 2017;197:182-90. https://doi.org/10.1016/i.juro.2016.07.087

Correspondence: Dr. Keith F. Rourke, Division of Urology, University of Alberta, Edmonton, AB, Canada; krourke@ualberta.ca 